University of Nebraska - Lincoln

DigitalCommons@University of Nebraska - Lincoln

Publications, Agencies and Staff of the U.S.

Department of Commerce

U.S. Department of Commerce

2009

\title{
Treatment of Northern Fur Seal (Callorhinus ursinus) Pups with Ivermectin Reduces Hookworm-Induced Mortality
}

\author{
Robert Delong \\ National Marine Mammal Laboratory, Alaska Fisheries Science Center, National Marine Fisheries Service \\ Anthony Orr \\ National Marine Mammal Laboratory, Alaska Fisheries Science Center, National Marine Fisheries Service \\ Ryan Jenkinson \\ University of California, Davis, California \\ Eugene T. Lyons \\ University of Kentucky, Lexington, Kentucky, elyons1@uky.edu
}

Follow this and additional works at: https://digitalcommons.unl.edu/usdeptcommercepub

Part of the Environmental Sciences Commons

Delong, Robert; Orr, Anthony; Jenkinson, Ryan; and Lyons, Eugene T., "Treatment of Northern Fur Seal (Callorhinus ursinus) Pups with Ivermectin Reduces Hookworm-Induced Mortality" (2009). Publications, Agencies and Staff of the U.S. Department of Commerce. 41.

https://digitalcommons.unl.edu/usdeptcommercepub/41

This Article is brought to you for free and open access by the U.S. Department of Commerce at DigitalCommons@University of Nebraska - Lincoln. It has been accepted for inclusion in Publications, Agencies and Staff of the U.S. Department of Commerce by an authorized administrator of DigitalCommons@University of Nebraska - Lincoln. 
MARINE MAMMAL SCIENCE, $* *(*): * * *-* * *(* * * 2009)$

No claim to original US government works

DOI: $10.1111 / j .1748-7692.2008 .00274 . x$

\title{
Treatment of northern fur seal (Callorbinus ursinus) pups with ivermectin reduces hookworm-induced mortality
}

\author{
Robert L. DeLong \\ ANTHONY J. ORR \\ National Marine Mammal Laboratory, \\ Alaska Fisheries Science Center, \\ National Marine Fisheries Service, \\ 7600 Sand Point Way, N.E., \\ Seattle, Washington 98115, U.S.A. \\ E-mail: robert.delong@noaa.gov \\ RYAN S. JENKINSON \\ Department of Evolution and Ecology, \\ University of California, \\ Davis, California 95616, U.S.A.

\section{EUGENE T. LYONS} \\ Department of Veterinary Science, \\ Gluck Equine Research Center, \\ University of Kentucky, \\ Lexington, Kentucky 40546-0099, U.S.A.
}

A breeding population of approximately 8,000-10,000 northern fur seals (Callorbinus ursinus) is located at San Miguel Island in the California Channel Islands. The population is increasing and produces about 2,500 pups annually (Melin et al. 2008). Pup mortality has increased during the past $10 \mathrm{yr}$ and has reached $50 \%$ or more in some recent years. Although we have not completed studies to describe the causes of this pup mortality, it appears that hookworm disease has been a major cause (Lyons et al. 2001).

Hookworm infections occur in very young northern fur seal pups. The hookworm larvae are transmitted to pups through the milk from the mother within the first few hours following birth and only for the first few days of the pup's life. Adult worms are present in pups beginning about 2 wk following birth (Lyons 1963, Olsen and Lyons 1965). Infections are thought to last for up to 3 mo until all adults are cleared from the small and large intestine of pups (Lyons et al. 2001).

Ivermectin is a broad-spectrum antiparasitic drug widely used for controlling arthropods and nematodes in domestic animals (Barragry 1987). Ivermectin, administered twice, $10 \mathrm{~d}$ apart, has been used to control nematodes in captive pinnipeds (Dailey 2001). The efficacy of a single dose of ivermectin was evaluated in a field setting for controlling hookworms (Uncinaria lucasi) with a small number $(n=4)$ of northern fur seal pups on St. Paul Island, Alaska (Beekman 1984). This field trial resulted in almost complete clearance of hookworm infections in treated pups. 
We conducted a study to assess whether a single treatment of ivermectin would increase northern fur seal pup survival. The goal was to assess whether pups receiving the ivermectin treatment cleared the infections, experienced increased growth and decreased mortality compared to control animals that received a saline placebo. An observed decrease in mortality for treated pups would constitute more evidence that hookworm disease has been a primary cause of the increased pup mortality recorded on San Miguel Island in recent years.

Pups were sampled from 8 to 10 July 2006 and from 18 to 20 July 2006 on the sandy beach habitat of Adams Cove, San Miguel Island. The two periods were chosen to obtain samples of pups born throughout the pupping season, which extends from 10 June through 31 July. A group of 300 northern fur seal pups were captured and treated either with ivermectin or a saline placebo. Pups were treated when they were approximately 2 wk old. A mobile blind was used to approach pup aggregations within reproductive territories. Pup aggregations generally consisted of pups whose mothers were away, feeding at sea. Pups associated with females were not captured so that very young and actively suckling pups were not disturbed. Individual pups were captured with a "noose pole" consisting of a noose fabricated from 4-mm plasticcoated cable and a telescoping paint roller pole that extended to $5 \mathrm{~m}$ in length. Pups were returned to the same reproductive territory after treatment.

Weight and length of each sampled pup were recorded. Pups were tagged with uniquely numbered pink Dalton Jumbo Rototags (Dalton ID Systems Ltd., Fort Atkinson, Wisconsin). ${ }^{1}$ Each pup was double-tagged along the trailing edge of the fore-flipper in the axilla just distal to the hair line.

Pups were alternately assigned to treatment and control groups to prevent any temporal or spatial pattern in pup selection throughout the capture process. Pups were injected subcutaneously in the lumbar region of the dorsum either with ivermectin (at a dose rate of $200 \mu \mathrm{g} / \mathrm{kg}$ ) or $0.9 \%$ saline (volume dose equal to that of ivermectin for a pup of the same weight). The ivermectin was prepared in a $1-\mathrm{mg} / \mathrm{mL}$ suspension of propylene glycol from more concentrated large animal ivermectin at the College of Veterinary Medicine, Colorado State University, Fort Collins, Colorado. Dosages ranged from 0.8 to $1.8 \mathrm{~mL}$, depending on the weight of each pup and were administered with a disposable syringe and a $21-\mathrm{ga} \times 2.5-\mathrm{cm}$ needle. Ivermectin was administered to 151 pups and 149 pups received a saline placebo.

A fecal sample was collected with a small animal fecal loop from all 300 pups when initially handled in July to assess prevalence of hookworm infections. Thirty-four pups from the treatment group and 30 control pups were recaptured on 10 and 11 August and fecal sampled (19-34 d after initial capture) to evaluate the longitudinal progress of the treatment and infections. The fecal samples were placed in $15-\mathrm{mL}$ centrifuge tubes containing $9.5 \mathrm{~mL}$ of seawater and were fixed at the end of each day by adding sufficient formaldehyde to create a $5 \%$ formalin solution. The quantity of fecal material obtained was scored numerically from 0 to 3 , with 0 being an empty loop and 3 being a loop filled with feces. Only samples that scored 1-3 were

\footnotetext{
${ }^{1}$ Reference to trade names does not imply endorsement by the National Marine Fisheries Service, NOAA.
} 
used in calculations for prevalence of infections. In the laboratory, the samples were centrifuged and the fluid was decanted. Saturated sugar solution was added to each test tube that was centrifuged again with a cover slip covering the top of the test tube (Lyons et al. 1988). Cover slips were examined at a magnification of 100 under a compound microscope. The presence or absence of hookworm eggs was recorded for each sample. All fecal samples were read blind so that the examiner did not know which samples were from treated or control pups.

Mortality surveys were conducted every $3-5 \mathrm{~d}$ following the treatment periods until mid-August when the mortality rate began to decline. Surveys were continued until early December at 14-20 d intervals. Control/treatment differences in observed mortality and hookworm egg prevalence were evaluated using Fisher's exact test for count data (Zar 1974). Tag numbers of observed dead pups were recorded during each survey.

In late September, about 2.5 mo following treatment, a sample of treated and control pups was recaptured to assess rates of growth between the two groups. Length and weight were recorded. Daily growth rates (kilograms/day) were used to standardize growth data for varying capture and recapture dates. Control/treatment differences in mass growth rate were evaluated using a Student's $t$-test (Zar 1974).

In total, 50 tagged control pups and 10 tagged ivermectin-treated pups were found dead during mortality surveys. No mortality was observed after the 27 September 2006 survey. The observed mortality rates of $6.6 \%$ (treatment) and $33.6 \%$ (control) were significantly different (Fisher's exact test, $P<0.00001$ ). The average growth rate of mass (kilograms/day) for pups treated with ivermectin was 0.057 (SE = $0.004)$. Growth rate for control pups was only $0.038(\mathrm{SE}=0.003) \mathrm{kg} / \mathrm{d}$, which was significantly less than for pups treated with ivermectin (Student's $t$-test; $t=3.17$, $\mathrm{df}=49, P=0.0026$ ).

The prevalence of hookworm eggs in fecal samples was identical (24\%) for 140 control and 140 treated pups at the time of treatment in July. By 11 August, when longitudinal fecal samples were collected, only 6\% (2 of 34) of pups from the ivermectin treatment group had feces positive for hookworm eggs, whereas the sample of control pups showed a significantly higher prevalence of infection at $67 \%$ (Fisher's exact test, $P<0.0001$ ), demonstrating the effectiveness of ivermectin in clearing the hookworm infections.

This is the first study to yield an estimate of prevalence of hookworm infections in the northern fur seal population at San Miguel Island. Hookworm eggs were found in a small proportion of the pups (24\%) at the time of treatment in late July, but increased to 67\% (20 of 30) of the control pups sampled again in August. The longitudinal fecal samples from control pups provided additional data for estimating prevalence of infection. Ten of 30 pups in the control group were shedding eggs in July, and 15 of the pups that had been negative for hookworm eggs in July were shedding eggs in August (Table 1).This is a total of 25 of 30 pups in the control group that were shedding hookworm eggs in either July or August. From this subset of animals, we calculate an $83 \%$ prevalence, which may be representative of the population, although the estimate is based on a small sample of pups. All dead pups handled at necropsy in past years have had hookworm infections (Lyons 
Table 1. Cross classification of presence (yes) and absence (no) of hookworm eggs in fecal samples of individual northern fur seal control pups $(n=30)$ sampled both during July and August 2006.

\begin{tabular}{lccr}
\hline \hline & & \multicolumn{2}{c}{ August } \\
\cline { 3 - 4 } & & No & Yes \\
\hline July & No & 5 & 15 \\
& Yes & 5 & 5 \\
\hline
\end{tabular}

et al. 2001). This is a biased sample as it is based only on dead pups rather than a cross-sectional sample of all pups on the rookery. Fecal samples taken from crosssectional samples of live pups handled in tagging studies in late September or early October have consistently been negative. This indicates infections have cleared from virtually all pups by early October when the youngest pup would be about 2 mo old.

Northern fur seal pups treated with ivermectin had a significant decrease in hookworm infection and an increased in growth and survival compared to those treated with the placebo. This appears to have resulted from treatment of pups when they were quite young (about 2 wk old) before the infections had become severe enough to initiate the cascade of changes that leads to death from hookworm disease. Two pups treated with ivermectin died soon after treatment (one within $16 \mathrm{~h}$ and one within $2 \mathrm{~d}$ ) and were examined at necropsy. The dead pup found $16 \mathrm{~h}$ following treatment had hookworm eggs in the feces at the time of treatment and the other pup did not. Both pups had small focal hemorrhages in the wall of the small intestine where adult hookworms appeared to have been attached, but neither pup had any hookworms attached to or in the contents of the small or large intestines. These observations indicate that the adult hookworms were killed and eliminated from the gut of one of the pups in less than $16 \mathrm{~h}$ following treatment with ivermectin. Necropsies were not conducted on the remaining 58 dead pups recovered during the study.

Northern fur seal pups treated with ivermectin exhibited increased growth rates and experienced significantly lower mortality than pups in the control group in this study. This confirms that hookworm disease has been responsible for much of the observed increase in pup mortality on San Miguel Island. The protocols we applied could be used in the future to assess whether roundworms are impacting growth or survival of pups in other pinniped populations.

\section{ACKNOWLEDGMENTS}

This study originated from discussions several years ago with Thierry Work. T. Spraker and F. Gulland provided advice for administering the treatments to pups. G. Orr, D. Watson, and E. Hamblen helped in capture and treating pups. M. DeLong provided assistance with recapture and fecal sampling pups. J. Laake assisted with experimental design and statistical analysis. The paper was improved by comments from B. Fadely, S. Tolliver, The Publications Unit of AFSC, the Editor and Assistant Editor of Marine Mammal Science, and two anonymous 
reviewers. The study was conducted under Marine Mammal Protection Act Scientific Research Permit \#782-1812.

\section{Literature Cited}

BARRAGRY, T. B. 1987. A review of the pharmacology and clinical uses of ivermectin. Canadian Veterinary Journal 28:512-517.

BeEKMAN, G. K. 1984. Clinical use of ivermectin against the hookworm (Uncinaria lucasi) of northern fur seal pups (Callorbinus ursinus). International Association of Aquatic Animal Medicine (IAAAM) Proceedings 1:50-54.

Dailey, M. D. 2001. Parasitic diseases. Pages 357-379 in L. A. Dierauf and F. M. D. Gulland, eds. CRC handbook of marine mammal medicine. Second edition. CRC Press, New York, NY.

LYONS, E. T. 1963. Biology of the hookworm, Uncinaria lucasi Stiles, 1901, in the northern fur seal Callorbinus ursinus Linn. on the Pribilof Islands, Alaska. PhD. dissertation. Colorado State University, Fort Collins, CO. 87 pp, 5 pls.

Lyons, E. T., J. H. DRudge AND S. C. Tolliver. 1988. Natural infection with Eimeria leucharti: Prevalence of oocysts in feces of horse foals on several farms in Kentucky during 1986. American Journal of Veterinary Research 49:96-98.

Lyons, E. T., S. R. Melin, R. L. Delong, A. J. OrR, F. M. Gulland and S. C. Tolliver. 2001. Current prevalence of adult Uncinaria spp. in northern fur seal (Callorbinus ursinus) and California sea lion (Zalophus californianus) pups on San Miguel Island, California, with notes on the biology of these hookworms. Veterinary Parasitology 97:309-318.

Melin, S. R., A. J. OrR AND R. L. DeLong. 2008. The status of the northern fur seal population at San Miguel Island, California, 2006-2007. Pages 45-58 in J. W. Testa, ed. Fur seal investigations, 2006-2007. U.S. Department of Commerce, NOAA Technical Memorandum NMFS-AFSC 188.

Olsen, O. W., AND E. T. LYONS. 1965. Life cycle of Uncinaria lucasi Stiles, 1901 (Nematoda:Ancylostomatidae) of fur seals Callorbinus ursinus Linn., on the Pribilof Islands, Alaska. Journal of Parasitology 51:689-700.

Zar, J. H. 1974. Biostatistical analysis. Prentice Hall, Inc., Upper Saddle River, NJ.

Received: 17 April 2007

Accepted: 29 October 2008 